\title{
A mixed-methods approach to evaluating student nurses changing answers on multiple choice exams
}

\author{
Rebecca A Cox-Davenport, Paula B Haynes, Theresa G Lawson \\ School of Nursing, Lander University, Greenwood, United States.
}

Correspondence: Rebecca Cox-Davenport. Address: School of Nursing, Lander University, Greenwood, United States. Email: rcoxdavenport@lander.edu

Received: J une 11, 2013

Accepted: August 18, 2013

Online Published: October 14, 2013

DOI : $10.5430 /$ jnep.v4n2p132

URL: http://dx.doi.org/10.5430/jnep.v4n2p132

\begin{abstract}
Using a mixed methods approach, the purpose of this study was to examine the perceptions and patterns of nursing student's changing answers on multiple choice exams. The sample of 86 students enrolled in an undergraduate nursing program were surveyed after their first exam of the semester. Exam response forms were examined for erasure marks to determine the answer changes on the exam grade; additionally, the relationship between self-reported school performance and frequency of changing answers, and self-reported anxiety and frequency of changing answers was examined. A qualitative exploration of two open-ended items included examining student perceptions about changing answers on unit exams. Five themes emerged from the qualitative exploration of how students felt about changing test answers: Educated gamble, confidence, anxiety learned, gut instinct and ambivalence. Three themes emerged from the analysis of the reasons students changed answers: Uncertainty, light bulb effect, and testing errors. The study's quantitative results indicated that although the student indicated anxiety regarding changing answers, a majority did so anyway. Moreover contrary to students' negative feelings regarding answer changing, most answer changing resulted in a modest improvement in their grade.
\end{abstract}

\section{Key words}

Changing answers, Student nurses, Multiple-choice exams

\section{Introduction}

Many schools of nursing utilize multiple-choice exams to evaluate a student's mastery of course content. There have been many studies to correlate the student's choice of changing answers with their exam grades. Although these studies have explored the practice of students changing answers on exams, this study sought to better understand student feelings about changing answers triangulated with their occurrences of changing answers and rating of test anxiety.

\section{Review of relevant literature}

The review of literature supported the fact that students expect an increase in their test grades by changing answers on an exam ${ }^{[3-5,7,8]}$ (see Table 1). A study by Neiswiadomy and colleagues supported the belief that cautious answer changing can lead to the student choosing the correct answer. Their study of 122 baccalaureate nursing students in their second semester of their junior year revealed that $86 \%$ of the students increased their scores when answers were changed on their 
exams. The study reported that 119 students made at least one change on various exams in the junior level courses. In this study, the number of changes ranged from 1 to 46 per student with a mean of 11.89 changes out of 540 questions. Although the percentage of changes was not very high, this study demonstrated that as a whole students gained from changing answers. Additionally, those students who made fewer changes tended to have higher test scores than those who made a large number of changes ${ }^{[6]}$.

Table 1. Findings of Reviewed Studies

\begin{tabular}{|c|c|c|c|}
\hline & Population & Variables & Findings \\
\hline $\begin{array}{l}\text { Benjamin, Cavell, \& } \\
\text { Shallenberger, } 1984\end{array}$ & & $\begin{array}{l}\text { Literature review of } \\
33 \text { changing answer } \\
\text { studies }\end{array}$ & $\begin{array}{l}\text { Most students changed answers from } \\
\text { incorrect to correct and } \\
\text { Students’ grades gained from changing answers. }\end{array}$ \\
\hline $\begin{array}{l}\text { Jordan \& Johnson, } \\
1990\end{array}$ & $\begin{array}{l}284 \text { Baccalaureate } \\
\text { Nursing students }\end{array}$ & $\begin{array}{l}\text { Changing answers } \\
\text { effect on test grade }\end{array}$ & $\begin{array}{l}\text { Students' grades gained from changing answers. } \\
\text { The students believed that they should not change answers on } \\
\text { exams. } \\
\text { Faculty who conveyed the idea of not changing answers. } \\
\text { Lower performing students benefited slightly less than higher } \\
\text { performing students when changing answers. }\end{array}$ \\
\hline $\begin{array}{l}\text { Gaskins, Dunn, } \\
\text { Forte, Wood, \& } \\
\text { Riley, } 1996\end{array}$ & $\begin{array}{l}12 \text { Nursing } \\
\text { students }\end{array}$ & $\begin{array}{l}\text { Qualitative } \\
\text { interviews }\end{array}$ & $\begin{array}{l}\text { Nursing students preferred not to change answers because } \\
\text { they believed it was not beneficial. } \\
60 \% \text { of students changed from incorrect to correct. }\end{array}$ \\
\hline $\begin{array}{l}\text { Ferguson, Kreiter, } \\
\text { Peterson, Rowat, } \\
\text { and Elliott, } 2002\end{array}$ & $\begin{array}{l}190 \text { medical and } \\
\text { physician assistant } \\
\text { student test } \\
\text { patterns on } \\
\text { computerized } \\
\text { exams }\end{array}$ & $\begin{array}{l}\text { Changing answer } \\
\text { patterns on } \\
\text { computerized exams }\end{array}$ & $\begin{array}{l}\text { There was low incidence of changing answers on the } \\
\text { computerized exam. } \\
\text { Students' grades gained from changing answers. }\end{array}$ \\
\hline $\begin{array}{l}\text { Neiswiadomy, } \\
\text { Arnold, \& Garza, } \\
2001\end{array}$ & $\begin{array}{l}122 \text { baccalaureate } \\
\text { nursing students }\end{array}$ & $\begin{array}{l}\text { Changing answers } \\
\text { effect on test grade }\end{array}$ & $\begin{array}{l}\text { Students' grades gained from changing answers. } \\
\text { Students that made fewer changes had higher exam grades. } \\
\text { Students reported faulty warning not to change answers. } \\
\text { Additional answer changes after the first change tended to be } \\
\text { from correct to incorrect. }\end{array}$ \\
\hline $\begin{array}{l}\text { Fischer, Herrmann } \\
\text { \& Kopp, } 2005\end{array}$ & $\begin{array}{l}36 \text { Medical } \\
\text { Students }\end{array}$ & $\begin{array}{l}\text { Changing answer } \\
\text { patterns on } \\
\text { computerized exams }\end{array}$ & $\begin{array}{l}\text { Students benefited when they changed answers on a test item } \\
\text { once. } \\
\text { Student saw no grade improvements with additional answer } \\
\text { changes. }\end{array}$ \\
\hline
\end{tabular}

The literature further revealed that faculty can give students a negative bias about changing answers ${ }^{[1,5,6]}$. Benjamin et al. ${ }^{[1]}$ revealed that only $15.5 \%$ of teachers believe that changing answers is beneficial. In addition, two thirds of the teachers advised students that changing answers would be detrimental to their grade. Jordan and Johnson ${ }^{[5]}$ conducted a study among 284 baccalaureate nursing students. The students surveyed revealed the belief that they should not change answers on exams. The students also revealed that it was faculty who conveyed the idea of not changing answers. According to the researchers, a majority of students 58\% changed answers from the incorrect to the correct answer. Of those students, it was determined that 53\% increased their test scores, and only $6.7 \%$ decreased their scores. Interestingly, the researchers were able to demonstrate that overall, changing answers benefited all students whether they were high, middle or lower third scorers in the class.

The use of exam response forms was a recurrent limitation in many of reviewed studies ${ }^{[3,5,6]}$. Researchers evaluating the forms could not be certain why the students changed answers. Ferguson, Kreiter, Peterson, Rowat, and Elliott ${ }^{[2]}$ attempted to remove the limitation of exam response forms by using computer software to evaluate student patterns of item response behavior on computer exams. Unlike with static exam response forms, these researchers were able to track students as they clicked and then changed answers. Ferguson et al. ${ }^{[2]}$ examined 190 medical and physician assistant student test 
patterns and found results similar to other studies regarding test scores in those who changed answers. The results revealed that the number of students who changed answers on the computerized exam in this study was found to be relatively low. Of the students that changed answers, an improvement in grades from 1-7 points on an exam was found. The investigators were also able to establish that students who spent more time on difficult questions often changed those questions more frequently ${ }^{[2]}$. Additionally, this study found statistically significant results that both low and high performing students enjoyed modest improvements in scores with 0.44 point and 0.70 point increase respectively in grades ${ }^{[1]}$. This contrasted with Jordan and Johnson's ${ }^{[5]}$ research that revealed lower performing students benefited slightly less than higher performing students when changing answers.

A qualitative research study by Gaskins et al. ${ }^{[4]}$ sought to better understand the reasons nursing students changed test answers. Their research supports that students change answers despite their beliefs or the advice they have been given discouraging this practice. The investigators interviewed 12 students of a convenience sample of 164 nursing students taking a given exam. Of the 12 students interviewed, $96 \%$ of the students changed answers and benefited from doing so. The highest number of changes was eight, and $60 \%$ of those changed an incorrect answer to a correct answer ${ }^{[4]}$. The researchers found that most students preferred not to change answers because they believed it was not beneficial. Among the students who did change answers, their most frequent reasoning included rereading the question and interpreting the question differently, rethinking the answers, and remembering information taught ${ }^{[4]}$. As in other studies, students reported mismarking the exam response forms as a common cause for changing their answer. Students explained that they would change an answer if they had initially guessed at the answer, and students admitted that they continually guessed at an answer when they decided to change it. Guessing on exams was reported by students when they knew they did not know the material ${ }^{[4]}$.

Other research has found mixed benefit to changing answers. Researchers Fischer et al. ${ }^{[3]}$ discovered students benefited when they changed their answers on a test item once but additional changes on that item did not improve scores. This study was conducted with a sample of 36 medical students taking a National Medical Board Examination and demonstrated that $55 \%$ of students changed their answers, and those changes yielded correct answers. The results of this study correlated with another study by Neiswiadomy et al. ${ }^{[6]}$ that demonstrated that one answer change on a single item was more beneficial than multiple changes, as additional answer changes tended to be from correct to incorrect.

\section{Methods}

Students from a rural Southeastern liberal arts college were recruited into this study following the University's Institutional Review Board Approval. Students were invited to participate in the study after taking their first nursing unit exam in the early part of the spring semester. Faculty not associated with the course gave students a flyer as they were leaving the testing room and asked them if they would like to complete a survey. Interested students were directed to a designated room inside the School of Nursing to receive study information, give informed consent, and complete the study instrument. Students included a self-selected four-digit numeric code on the consent form and study instrument to allow investigators to link survey responses with exam response forms. Course faculty deidentified exam response forms by replacing student names with the self-selected four-digit numeric codes and submitted the exam response forms to the investigators.

The purpose of Phase I of the study was to examine the pattern of student answer changing on unit examinations. Exam response forms were examined for eraser marks to determine the degree to which student changed their answers during the course of the examination, and these findings were compared to the self-reported student factors detailed in the study instrument. The investigators then determined whether the change of answer(s), as evidenced by eraser marks on the exam response forms, altered the overall test grade in a positive or negative way. 
The purpose of Phase II of the study was to examine student perceptions about changing answers on unit exams. The tool for this phase was developed by the researchers, and face validity was established by the members of the nursing school's faculty. The goal of this phase was to capture student feelings about changing answers and test anxiety. Students were first asked two open ended questions about how they generally felt about changing answers on an exam and if they made any changes on this exam reason they made the changes. The participants were also asked to report if they were an A student, A-B student, B student, B-C student, or C student. Next the students were asked to rate their anxiety on the current exam from "Not Anxious", "Somewhat Anxious", "Moderately Anxious", and lastly "Very Anxious". Lastly students were asked about their overall test anxiety using the same scale. Subject responses were transcribed and checked for accuracy.

All levels of the school of nursing are represented in the sample from sophomore to senior levels, but due to scheduling conflicts, second semester sophomores could not be sampled. There were as many as 33 students in each level, with the range being from 11 to 33 students per level. As part of using a multi-method research design, the authors of this study used both the qualitative and quantitative survey questions to triangulate students' overall feelings about changing exam answers and their reasons for changing answers to test items on the exam. The quantitative analysis of the data included Chi-squared tests to determine whether there was a relationship between frequency of changing answers and test performance from Phase I, and the self-reported school performance and test anxiety.

The data from the open ended questions was analyzed using qualitative techniques. Investigators independently applied a qualitative systematic approach to code the content of the transcripts. Each researcher identified categories and recurring themes. Interrater reliability was established between investigators as themes emerged and were combined; if variances among themes occurred, differences were discussed and consensus was obtained ${ }^{[7]}$. From their comments several themes emerged. The themes were present in every class level from the sophomore through senior level students.

\section{Results}

\section{Qualitative analysis}

\section{Themes from question one: "How do you feel about changing answers?"}

Theme 1: Educated Gamble. Students revealed that they had a great sense of worry about changing their answers, and often described changing answers as a risk. Students described feeling anxiety and discomfort with the action of changing answers. But they made answer changes despite being worried about their changes and often having feelings of regret. One student described this feeling as "there is a gamble with or without changing." The students made their changes although their actions were contradictory to what one student described as a "nagging doubt" that seemed unsettling. One student also wrote "I shouldn't do it when I am in doubt, but I am very known to do it."

Theme 2: Confidence. Students also expressed that they only changed answers when they felt sure that they had made an error with their first answer. Feeling a level of certainty in an answer change stemmed from the student's thinking of or finding new information about that test item topic. Students expressed that they may be prompted by information in another test question, and this new information gave them the confidence to change answers. One student stated "I go back to change an answer on the test because I remembered or had a trigger from answering other questions; it is beneficial." Under this theme, there was a strong subtheme of needing a solid reason to change an answer. Students-reflected the necessity of having a solid rationale for the change gave the student more confidence in the answer change. One student said, "I do not normally change answers unless I am sure the answer was wrong before."

Theme 3: Anxiety Learned. Students also reported that they try not to change answers based on the direction of faculty and their negative experience with answer changes. Faculty did influence the way the students in the sample approached changing answers. One student described the guidance given by faculty as, "I'm better off not changing answers as I've 
always been told. Should always go with your first response.” The context of this learned testing method coming from faculty cannot be verified by this study. Many students contended that faculty instructed students not to change answers; they stated that they followed this advice. Outside of faculty statements, students also reported that their past experiences influences how they approach current tests. Students reported strong opinions to never change answers. One student stated, "I hardly ever change answers on the test because from past experience it has always proved wrong."

Theme 4: Gut Instinct. The concept of students depending on gut instinct when faced with a question that they are unsure of resonated within the sample. Students described the importance of having an initial reaction to a group of answers-and following the answer they felt was best on their first read. Students described using the experience of trusting their first impressions as an important judgment tool when choosing between two answers. One student responded "I feel that one's initial response is always the most correct unless the student has misread the question.” Another student stating emphatically that, "My first choice was always right."

Theme 5: Ambivalence. A minority of students described feeling ambivalent about the idea/practice of changing answers. This group of students did not rate themselves as anxious test takers, and were without strong opinion about changing a test answer. Students depicted changing answers as good and bad for test outcomes-and did not show commitment to a strategy one way or the other. Students reported feeling "indifferent" to changing answers, and these students were unsure if it helped their grade stating "Sometimes it’s beneficial and sometimes not."

\section{Themes from question two: "What was your reason(s) for changing answers on this exam?"}

The researchers of this study also explored the reason for changing answers on the exam the students just took. The researchers asked, "What was your reason(s) for changing answers on this exam?” The themes were similar to the students overall philosophy for changing answers. However, the more acute reasons for changing answers had some variance from the first question, and from the student responses three themes emerged.

Theme 1: Uncertainty. Students expressed feeling confused about content, and this confusion caused them to question their first response. Students described the process of narrowing their response down to two, and not feeling sure of their answers thus causing them to change answers. One student wrote, "Unsure if I was relating the answer to the correct subject." While another described this feeling of uncertainty as "The answer choices I narrowed down were tricky. The answer I first chose upon reflection, didn't make sense so I changed my answer.”

Theme 2: Light bulb effect. The "Light bulb" theme emerged from the way answers popped into the student's head during the test. Students described test question wording which gave them the answer, but they also described remembering content as they progressed in the exam. This is similar to the previously mentioned theme of "Confidence". One student stated "After seeing other questions that triggered my memory, I did not feel good about my first response." Students also described spontaneously remembering information later in the test and changing answer by stating "Thought about the question more in-depth and walked through the question more thoroughly.”

Theme 3: Testing errors. Students described making errors on the exam response form and errors from rushing as they filled in answers. This theme was not surprising based on the literature review, but reinforced to the limitations of this study. Seven students of the 86 in the sample reported that they had made a clerical error on the exam, but of the seven students three had a mix of reasons for changing answers not only testing errors.

\section{Quantitative results}

Eighty six students were recruited into the sample $(n=86)$. Students were asked to give information about their grades and their level of test anxiety. Students rated their grades on a 1-5 scale with a 1 being an "A" student and a "C" student 
quantified as a 5. No student described himself or herself as a "C" only student on the scale. The mean score for the sample was 2.884, which would place this sample between "B" and “A-B" students.

Students also described their level of testing anxiety with the unit exam they had just completed and their overall test anxiety. Students rated their anxiety on a 1-4 scale with 1 being not anxious and 4 being very anxious. The mean anxiety rating for the current exam was 2.616 on the unit exam compared to student's general exam anxiety mean of 2.43. The data were collected after the first unit exam of the semester that could account for there being greater anxiety on this test than students' usual test anxiety.

Course faculty examined the frequency of changing answers on the "bubbled in" type of exam response forms. Researchers looked at each exam response form for eraser marks indicating changed answers from right answer to wrong answer, wrong to right, and right to wrong. There were 83 total changes found on the exam response forms. Forty-five percent of students changed their answers to the correct answers, and 33\% of students changed answers to the wrong answers. Twenty percent of students changed their answers from a wrong answer to another wrong answer.

The effect on the test grade was analyzed using a chi square test. The analysis showed that for changing answers from correct to incorrect there is a significant relationship on the effect on grades $\mathrm{n}=86, \mathrm{df}=9$, Chi-square $=35.837, p<.000$. Incorrect to correct had lesser impact on course grade $\mathrm{n}=86, \mathrm{df}=9$, Chi-square $=28.930, p<.001$, but still held a significant relationship to the test grade. Upon examination, the significant result explained that answer changes did not positively affect grade outcomes. Students changed answers, but many of the wrong answer changes had no effect or canceled out other positive changes made by students.

Student anxiety was then examined for an impact on answer changing. Students that self-reported as generally having high test anxiety made the fewest changes on their exam response forms (see Table 2). The most likely students to change answers were students that rated themselves as a "the somewhat anxious student". It is interesting to note that highly anxious students did not go back and change more answers. One of these highly anxious students described making a commitment not to change answers and "just move on" once they had chosen an answer. This is an example of how a highly anxious student can take a teacher's advice as a universal declaration that may not be the best in every situation. It is noteworthy that both changes made by the highly anxious students were to the wrong answer.

Table 2. Frequency of Answer Changes Compared to General Test Anxiety Self-report Level

\begin{tabular}{llll}
\hline $\begin{array}{l}\text { General Test Anxiety } \\
\text { Self-report }\end{array}$ & $\begin{array}{l}\text { Wrong answer to Wrong } \\
\text { answer }\end{array}$ & $\begin{array}{l}\text { Right answer to Wrong } \\
\text { answer }\end{array}$ & $\begin{array}{l}\text { Wrong answer to Right } \\
\text { answer }\end{array}$ \\
\hline Level 1 & 3 & 1 & 2 \\
Level 2 & 6 & 13 & 24 \\
Level 3 & 12 & 12 \\
Level 4 & 8 & 2 & 0 \\
& 0 & 28 & 38 \\
\hline
\end{tabular}

\section{Discussion}

This study's purpose was to examine the perception and the patterns of students changing exam answers. The impetus for this study was the seemingly pervasive nursing student statement "I always change to the wrong answer". However the literature and the results of this study supports that students do make changes that benefit their grades with judicious changes in answers on exams ${ }^{[3,5,6,8]}$. In this study only three students identified a positive experience with changing answers, yet the students had a modest gain in their overall exam scores. 
The review of the literature also supported this study's qualitative findings that students rely on using their first hunch or their "gut instinct" to make a final decision on an exam answer ${ }^{[4,5]}$. Additionally, Gaskin's research supported the finding that students may be triggered by subsequent exam questions to help them make decisions about changing answers.

The results of this study also showed that students had unnecessary anxiety about changing answers that seemed to stem from faculty advice that they should not change an answer. The literature also supports this general belief held by students and faculty that changing answers could be damaging to their grade ${ }^{[4-6]}$. Students in this study seemed to latch on to the absolutes in faculty advice-and did not take into consideration other suggestions that changing answers can be beneficial under certain circumstances.

An area of faculty intervention could include the unsettled feeling of students about changing answers. One student stated "It makes me feel anxious and nervous, and I have a higher chance of missing future questions because I begin to worry about my grade." Faculty could ease the sense of worry that appeared to be a pervasive feeling by discussing how to thoughtfully change answers. Faculty could make a point to show students when changing answers might positively or negatively affected their grade. Showing students the benefits of changing could help them to be stronger test takers and decrease their overall anxiety about changing answers.

The limitations of this study included the fact that it is a convenience sample in a single school of nursing. Despite the single site, there was diversity in the students having surveyed five of the six levels of the student population. Another limitation found in the data analysis was that no students rated themselves as $C$ students most rated themselves as a $B$ to A-B student. The researchers did not did not specify for students to give their overall nursing grades, and this question gave a skewed representation of student grades.

There was also no way for researcher to ask students directly about their missed questions because student forms were de-identified. Therefore the researchers could not tease out testing errors from true answer changes. Seven students in the sample identified testing errors as one of the reasons they changed answers. This limitation was also found in the other studies, and it is important to recognize that student's may have made simple mistakes when transferring answers over to the exam response forms and not a true answer change.

\section{Conclusion}

Student nurses in this sample appear to have a negative attitude toward changing answers although it may have a positive effect on their grade or at the very least no loss with a balance of answer changes. The theme related to faculty influence on students changing answers appears also to be negative. Students reported that faculty warn students not to change answers, when this study and many in the literature find student benefits to answer changing. This could be an area of faculty impact to teach student test taking skills to make educated answer changes. Students also reported a theme of uncertainty with changing answers. Faculty could also impact student test taking by discussing the difference between the theme of the "light bulb effect" and changing answers based on uncertainty.

\section{References}

[1] Benjamin, L.T., Cavell, T.A., \& Shallenberger, W.R. Staying with initial answers on objective tests: Is it a myth? Teaching of Psychology. 1984; 11(3): 133-141.

[2] Ferguson, K., Kreiter, C., Peterson, M., Rowat, J., \& Elliott, S. Is that your final answer? Relationship of changed answers to overall performance on a computer-based medical school course examination. Teaching and Learning in Medicine. 2002; 14(1): 20-23. PMid:11865744 http://dx.doi.org/10.1207/S15328015TLM1401_6

[3] Fischer, M., Herrmann, S., \& Kopp, V. Answering multiple-choice questions in high-stakes medical examinations. Medical Education. 2005; 39(9): 890-894. PMid:16150028 http://dx.doi.org/10.1111/j.1365-2929.2005.02243.x 
[4] Gaskins, S., Dunn, L., Forte, L., Wood, F., \& Riley, P. Student perceptions of changing answers on multiple choice examinations. Journal of Nursing Education. 1996; 5(2): 88-90.

[5] Jordan, L., \& Johnson, D. The relationship between changing answers and performance on multiple-choice nursing examinations. Journal of Nursing Education. 1990; 29(8): 337-340. PMid:2175771

[6] Nieswiadomy, R., Arnold, W., \& Garza, C. Changing answers on multiple-choice examinations taken by baccalaureate nursing students. Journal of Nursing Education. 2001; 40(3): 142-144. PMid:11302544

[7] Richards, L. Handling Qualitative Data. (2nd ed.). Thousand Oaks, CA: Sage Publishing. 2009.

[8] Waddell, D., \& Blankenship, J. Answer changing: a meta-analysis of the prevalence and patterns. Journal of Continuing Education in Nursing. 1994; 25(4): 155-158. PMid:8046051 